\title{
Análise de Propostas de Ensino Baseadas em QSC: Uma Revisão da Literatura na Educação Básica
}

\section{Analysis of SSI-Based Teaching Proposals: A Literature Review in Basic Education}

\section{Grégory Alves Dionor ${ }^{a, b}$; Dália Melissa Conrado ${ }^{c}$; Liziane Martins ${ }^{a, d}$; Nei de Freitas Nunes Neto ${ }^{\mathrm{e}}$}

a Universidade Federal da Bahia, Salvador, Brasil - gadionor.bio@gmail.com

b Departamento de Educação, Universidade do Estado da Bahia, Teixeira de Freitas, Brasil

c Faculdade de Educação, Universidade Federal da Grande Dourados, Dourados, Brasil - profdalia@gmail.com

d Instituto de Humanidades, Artes e Ciências, Universidade Federal do Sul da Bahia, Teixeira de Freitas, Brasil lizimartins@gmail.com

e Faculdade de Ciências Biológicas e Ambientais, Universidade Federal da Grande Dourados, Dourados, Brasil nunesneto@gmail.com

\section{Palavras-chave:}

Educação científica.

Educação CTSA.

Propostas de ensino.

Análise de conteúdo.

\section{Keywords:}

Scientific education.

STSE education.

Teaching proposals.

Content analysis.
Resumo: Considerando a importância de se caracterizar estratégias didáticas sobre questões sociocientíficas (QSC) para avaliar as propostas executadas no contexto do ensino das ciências naturais na Educação Básica, analisamos propostas de ensino baseadas em QSC presentes na literatura, por meio de uma revisão sistemática de artigos levantados em bases de dados nacionais e internacionais. Nos 34 artigos analisados, observamos as definições sobre QSC e dificuldades relatadas, como as resistências encontradas, a falta de materiais adequados, a deficiência na formação docente, e a dificuldade dos próprios discentes. Porém, os trabalhos apontam que o ensino baseado em QSC colabora na construção de uma educação científica contextualizada e alinhada com a educação CTSA, auxilia na formação de cidadãos críticos e sociopoliticamente ativos, mobiliza outros conhecimentos e dimensões dos conteúdos, entre outras vantagens. Nesse sentido, compreendendo melhor sobre essa literatura, poderemos delinear com maior qualidade futuros projetos na área.
Abstract: Considering the importance of characterizing didactic strategies about Socioscientific Issues (SSI) to evaluate the proposals made in the context of the teaching of the natural sciences in basic education, we analyze SSI-based teaching proposals in the literature, through a systematic review of articles raised in national and international databases. In the 34 articles analyzed, we observed the definitions of SSI and reported difficulties, such as the resistance found, the lack of adequate materials, the deficiency in teacher training, and the difficulty of the students themselves. However, the work shows that SSI-based education contributes to the construction of a scientific education that is contextualized and in line with STSE education, helps in the formation of critical and sociopolitically active citizens, mobilizes other knowledge and dimensions of content, among other advantages. In this sense, understanding better about this literature, we will be able to delineate with better quality future projects in the area. 


\section{Contextualização}

Uma das estratégias pedagógicas ${ }^{1}$ que vem acompanhando algumas das demandas da educação científica, no que concerne às metodologias inovadoras e à formação cidadã atrelada ao desenvolvimento do espírito crítico dos alunos, é o uso de Questões Sociocientíficas (QSC) como estruturadoras de propostas didáticas. Esta estratégia, além de poder melhorar o processo formativo para a cidadania, tem, nos últimos anos, despertado o interesse de inúmeros pesquisadores.

As QSC são consideradas como controvérsias de caráter científico transdisciplinar, polêmicas e geralmente não apresentam apenas uma solução. Elas demandam uma tomada de decisão, necessitando desde conhecimentos de várias disciplinas até reflexões éticas e morais acerca dos problemas envolvidos (SADLER, 2004a; JIMÉNEZ-ALEIXANDRE; FREDERICO-AGRASO, 2006; SADLER; DONNELLY, 2006).

Ademais, as QSC podem ser entendidas como problemáticas de cunho social que trazem enlaces conceituais e/ou tecnológicos com os contextos científicos e a esfera ambiental (SADLER, 2005; REIS; GALVÃO, 2009) e que podem ser utilizadas como base para a abordagem de conteúdos no contexto educacional (CONRADO, 2017). Exemplificando, os debates de assuntos como clonagem, utilização de animais para testes, pesquisas acerca do genoma, gerenciamento de componentes naturais como os biocombustíveis, dentre outros, que possuem fortes implicações científicas, tecnológicas, políticas e ambientais, podem ser consideradas como QSC possíveis de serem abordadas em sala de aula (MARTÍNEZ-PÉREZ; CARVALHO, 2012; CONRADO; NUNES-NETO, 2018a).

Especificamente no cenário educacional, as QSC podem ser utilizadas como estratégias didáticas, visto que o ensino baseado em QSC, por meio de propostas didáticas, possibilita, por exemplo, o desenvolvimento de habilidades argumentativas, de tomada de decisões, do pensamento crítico e da ação sociopolítica nos estudantes, ainda abarcando o ensino dos conteúdos específicos das disciplinas (ZEIDLER; NICHOLS, 2009; SOLBES, 2013; MARTÍNEZ-PÉREZ, 2014; CONRADO, 2017).

Diversas pesquisas e atividades (e. g. JIMÉNEZ-ALEIXANDRE; FREDERICOAGRASO, 2006; SADLER; DONNELLY, 2006; REIS; GALVÃO, 2009; ZEIDLER; NICHOLS, 2009; MARTÍNEZ-PÉREZ et al., 2011; SANTOS et al., 2011; MARTÍNEZPÉREZ, 2012; 2014; MARTÍNEZ-PÉREZ; CARVALHO， 2012; SOLBES， 2013; CONRADO; NUNES-NETO, 2018a) procuram investigar as possibilidades advindas do uso

\footnotetext{
${ }^{1}$ A escolha pelo uso deste termo advém do fato de que, conforme Silva (2016), embasada nos estudos de Edgar Morin, a ideia de 'estratégia' abarca a imprecisão, a variabilidade e a diversidade de fatores inerentes às ações educacionais planejadas e realizadas, ou seja, que essas intervenções podem sofrer uma série de interferências imprevistas, necessitando, dessa forma, de constantes avaliações e novos posicionamentos. Ademais, conforme a mesma autora, as estratégias, apesar de exigirem um método, consideram não só o modo de condução, mas o contexto nos quais as atividades serão desenvolvidas.
} 
de propostas de ensino baseadas em Questões Sociocientíficas no contexto da sala de aula. Porém, percebemos uma carência de pesquisas voltadas à construção e à utilização de quadros teóricos, visando, sobretudo, uma clareza conceitual na área de Ensino de Ciências (LEVINSON, 2006; KAHN; ZEIDLER, 2017). Consequentemente, temos uma falta de trabalhos que visem o estabelecimento de fundamentos teóricos do uso de QSC na educação científica (CONRADO, 2017), bem como que avaliem características das propostas de ensino. Deste modo, torna-se evidente a necessidade de pesquisas que se voltem para as discussões acerca do ensino baseado em QSC, como os estudos de revisão da literatura, pois estudos dessa natureza nos auxiliam a entender como o conhecimento científico acerca da temática vem se construindo e quais são as principais contribuições e lacunas existentes (BELL, 2005).

Assim, nesta pesquisa, buscamos responder as seguintes questões: como se apresentam, na literatura, as propostas de ensino baseadas em QSC para a educação básica? Em que contextos e sob quais embasamentos teóricos estas pesquisas estão sendo realizadas? $\mathrm{Na}$ literatura, quais resultados sobre a pesquisa relacionada ao uso de QSC em propostas de ensino podem ser observados?

A partir disso, nesse trabalho, descrevemos e analisamos propostas de ensino baseadas em QSC presentes na literatura de bases/bancos de dados nacionais e internacionais, focando nos pressupostos teóricos e resultados encontrados na aplicação dessas propostas.

\section{Procedimentos metodológicos}

Esta é uma pesquisa qualitativa de caráter descritivo-exploratório, por buscar construir um quadro panorâmico (DEMO, 1985) acerca da utilização de questões sociocientíficas em estratégias didáticas no ensino de ciências naturais de níveis da educação básica. Assim, realizamos uma pesquisa bibliográfica, por meio de uma revisão sistemática da literatura, entendendo aqui esta modalidade como aquela que busca explorar materiais já desenvolvidos, como artigos científicos (GIL, 2017). A escolha pela revisão sistemática se deu por esta utilizar-se de um método de pesquisa transparente e rigoroso cientificamente, minimizando, assim, alguns graus de enviesamento dentro dos critérios estabelecidos nesta pesquisa, ao mesmo tempo em que é realizada uma busca exaustiva da literatura acerca da temática (RAMOS et al., 2014)., caracterizando uma amostra não probabilística intencional (CERVO; BERVIAN, 2002; GIL, 2017). Ressaltamos ainda que o presente trabalho se insere no contexto de um projeto de pesquisa maior realizado no mestrado do primeiro autor (DIONOR, 2018).

Para uma melhor estruturação e compreensão da pesquisa, dividimos o percurso metodológico empregado neste trabalho em três etapas. Para a primeira etapa - o levantamento da literatura - , buscamos em bancos/bases de dados os trabalhos que traziam 
propostas de ensino baseadas em QSC, para que pudéssemos, a partir da análise destes trabalhos, compreender com quais finalidades e em que contextos as propostas didáticas tinham sido utilizadas.

Os bancos/bases de dados selecionados foram atas de eventos e sites de indexação de periódicos. Dentre os eventos, investigamos: (i) atas do Seminário Ibero-Americano de CTS, por este ser um importante evento internacional que abarca discussões também sobre Questões Sociocientíficas, agregando pesquisadores tanto latino-americanos, quanto europeus, com uma ampla produção consolidada acerca da temática (GONÇALVES; SILVA, 2017); (ii) atas do Encontro Nacional de Pesquisa em Educação em Ciências - ENPEC, visto que este é considerado o evento mais importante da área de Educação em Ciências em território nacional, além de um espaço propício para que professores relatem e discutam suas práticas (AGUIAR; CABRAL, 2007; VENTURI; MOHR, 2011), bem como por abarcar produções de diversos programas de pós-graduação, visto que muitos pós-graduandos de programas de Ensino de Ciências e áreas afins buscam submeter e apresentar suas pesquisas neste evento, logo, o ENPEC acaba por abarcar, em suas apresentações, recortes de pesquisas de dissertações e teses (SOUSA; GEHLEN, 2017).

Já entre os sites de indexação de periódicos, buscamos no: (iii) Scientific Electronic Library Online - SciELO (<http://www.scielo.org/php/index.php $>$ ), por este indexar cerca de 1.440 periódicos, além de sua representatividade dentro do cenário latino-americano (SCIELO, 2017); (iv) Education Resources Information Center - ERIC $(<\mathrm{https}$ ://eric.ed.gov/>), por ser uma das maiores bibliotecas digitais acerca das discussões de Educação, com mais de 1.070 periódicos indexados (ERIC, 2017); e (v) Scopus (<https://www.scopus.com/>), por possuir cerca de 22.000 periódicos indexados, sendo considerada uma das maiores bases de dados acadêmicas do mundo (SCOPUS, 2017).

Nestes bancos/bases, utilizamos uma série de palavras-chave para a busca, sendo a lista final de palavras-chave definida através da adaptação da oscilação entre o método indutivo e dedutivo de saturação utilizado por Pedretti e Nazir (2011) ${ }^{2}$ : Tema controverso; Tema controverso sociocientífico; Tema / Temática sociocientífico(a); Problema sociocientífico; Controvérsia sociocientífica; Caso sociocientífico; Discussão sociocientífica; Situação sociocientífica; Assunto sociocientífico; Tópico sociocientífico; Dilema sociocientífico; Debate sociocientífico; Questão sociocientífica; Questão socialmente

\footnotetext{
${ }^{2}$ Iniciamos a relação de palavras-chave com uma abordagem indutiva, utilizando termos relativos a Questões Sociocientíficas conhecidos por nós a partir de nossas leituras e experiências. A partir desses termos, realizamos algumas buscas nos bancos/bases de dados selecionados e, diante das leituras iniciais dos trabalhos que surgiam, fomos, dedutivamente, percebendo novas formas, presentes na literatura, de se referir às QSC. As buscas iniciais continuaram nos bancos/bases de dados até o ponto de saturação, em outras palavras, quando não encontrávamos novas palavras-chave a serem incluídas no rol desta pesquisa. De modo informal, tal qual as autoras, a lista de termos com suas respectivas traduções foi discutida entre os autores do trabalho, o que auxiliou no refinamento da lista final de palavras-chave que foram utilizadas na pesquisa.
} 
controversa; Questão socialmente viva; Questão socialmente aguda. Procurávamos estes termos no título, no resumo e nas palavras-chave dos trabalhos, tendo sido o levantamento realizado entre os meses de agosto e dezembro de 2016. As buscas também foram realizadas a partir de suas traduções para inglês e espanhol, além de variações de escrita como plural e uso de hífen.

Nos sites, as buscas foram feitas sem restrição de datas, ou seja, cobrindo todo o intervalo de tempo disponibilizado nos mesmos. O ENPEC é realizado bianualmente, sendo a primeira edição em 1997 e a última, até o momento da pesquisa, (a décima) em 2015, mas não tivemos acesso às atas da $2^{\mathrm{a}}$ edição (1999); o SIACTS também acontece bianualmente, sendo a primeira edição em 2000 e a última (a nona) em 2016 e não tivemos acesso às atas da $1^{\text {a }}$ (2000) e da $3^{\text {a }}$ (2004) edições, porém acreditamos que isto não traga um prejuízo significativo aos resultados, pois, além do número de trabalhos submetidos nas primeiras edições ser menor, estas edições ocorreram em um período no qual as discussões acerca do ensino baseado em QSC ainda estavam se consolidando. Após o primeiro levantamento, os artigos passaram por uma filtragem (Figura 1) para seleção daqueles que consideramos pertinentes para o presente estudo.

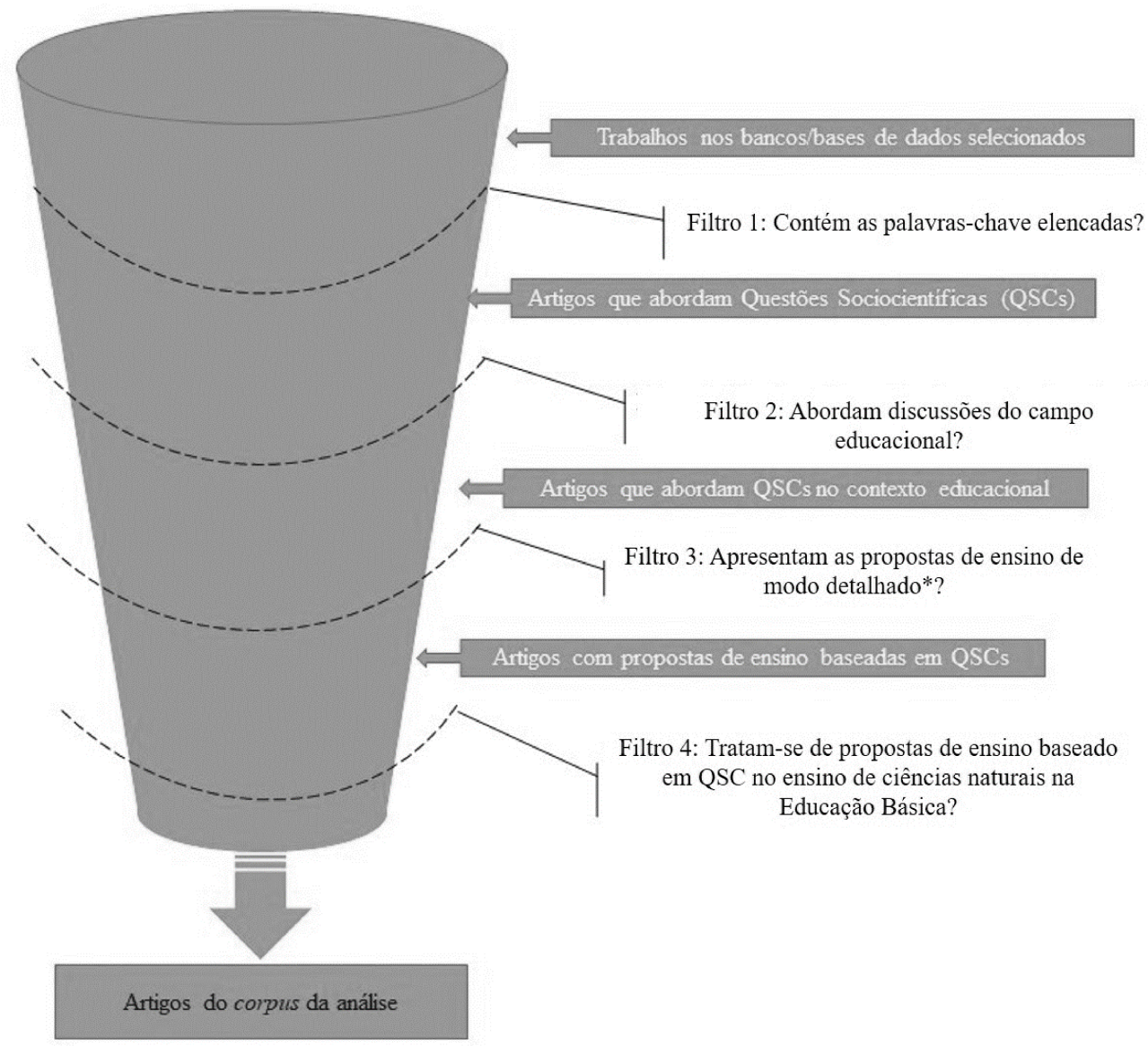

Figura 1 - Esquema de filtragem para seleção de artigos para o corpus de estudo da pesquisa.

*Consideramos aqui aqueles trabalhos que mencionem a Questão Sociocientífica a ser tratada e tragam certo detalhamento da proposta executada (cf. CONRADO, 2017; CONRADO; NUNES-NETO, 2018b).

Fonte: Elaborada pelos autores. 
A partir das palavras-chave, encontramos um total de 913 materiais (70 nas atas do ENPEC, 50 nas atas do SIACTS, 234 no SciELO, 53 no ERIC e 506 no Scopus). Só consideramos para a pesquisa apenas artigos completos em português, inglês e espanhol, por acreditarmos que tais trabalhos já passaram por um crivo da comunidade acadêmica no processo de submissão aos periódicos e eventos e, além de tais idiomas abarcarem as principais produções na área, o número de falantes destes idiomas, se somados, aproxima-se de 1,028 bilhões de pessoas (SIMONS; FENNIG, 2017). Não incluímos no levantamento aqueles artigos que não estavam disponíveis para livre acesso (gratuito) e eliminamos os repetidos, restando, assim, 490 artigos.

$\mathrm{Na}$ segunda filtragem, buscamos, a partir dos resumos, quais os trabalhos que abordavam as QSC relacionadas a contextos educacionais; selecionamos, assim, 346 artigos. Nestes artigos, realizamos uma leitura flutuante, buscando aqueles com propostas de ensino baseadas em QSC que traziam alguma descrição mais pormenorizada da proposta, como contexto de aplicação, questões norteadoras, objetivos de aprendizagem e/ou detalhes/instruções para implementação (cf. CONRADO, 2017; CONRADO; NUNESNETO, 2018b); este trata-se do terceiro filtro, do qual resultaram 66 artigos. Por fim, dentre esses, buscamos aquelas realizados no contexto do ensino das disciplinas das ciências naturais (Biologia, Química e Física) ou interdisciplinar entre elas, ocorridas na educação básica (Ensino Fundamental, Médio, Técnico Integrado ao Médio, e correspondentes em outros países), totalizando 34 artigos que constituíram o corpus de análise de nossa pesquisa, dos quais 14 foram publicados em atas de Eventos e 20 em periódicos indexados nas bases de dados. A partir deste total de trabalhos, conseguimos ter um olhar sobre como o ensino baseado em QSC tem sido abordado nesse recorte da literatura e as contribuições desses trabalhos para o desenvolvimento do campo de pesquisa em educação científica.

A partir dos artigos selecionados para constituir o corpus da pesquisa (artigos com aplicação de propostas de ensino baseadas em QSC), foi realizada a análise de conteúdo (BARDIN, 2011), considerando os seguintes critérios: conceitos sobre QSC adotados para a elaboração das propostas de ensino; contextos nas quais as propostas foram usadas; e as possibilidades/vantagens e dificuldades/limitações encontradas pelos professores e pesquisadores envolvidos. As categorias analíticas foram definidas a priori, sendo refinadas após a leitura flutuante, passo essencial da análise de conteúdo, pois, com ela, podemos ter um contato com as mensagens veiculadas nos textos, percebendo assim - após a análise em si (i.e., a coleta e a categorização dos dados) -, se as categorias são suficientes para a investigação proposta ou se precisam de adaptações/melhorias (BARDIN, 2011). Na segunda etapa da pesquisa - a análise descritiva -, cada artigo, após ser (1) identificado, foi analisado, buscando qual a definição de Questões Sociocientíficas adotada pelos autores, bem como 
quais os referenciais por eles utilizados (enquanto líamos, anotávamos os referenciais utilizados pelos autores dos artigos do corpus da pesquisa, listando, ao final, aqueles mais recorrentes).

Após isso, na terceira etapa - a análise dos resultados - dentro dos resultados trazidos pelos autores (4), discutimos as possibilidades e/ou vantagens, assim como as dificuldades e/ou limitações por eles atribuídas ao uso de QSC.

A fim de aumentar a validade interna do estudo, análises independentes foram realizadas por três pesquisadores colaboradores com familiaridade com os referenciais teórico-metodológicos da pesquisa (LECOMPTE; GOETZ, 1982). A taxa de concordância entre estas análises atingiu 83\%, indicando maior confiabilidade das análises. Após as análises dos pesquisadores, nos casos de discordância (17\%), a decisão ficou a cargo do pesquisador responsável pela pesquisa. Sendo assim, os resultados apresentados e discutidos abaixo são fruto de uma consonância obtida a partir das análises independentes.

\section{Resultados e discussão}

Considerando os critérios de seleção descritos anteriormente, o corpus da pesquisa foi composto por 34 artigos (Quadro 1). 
Quadro 1 - Trabalhos selecionados e analisados.

\begin{tabular}{|c|c|c|c|}
\hline Código & Autores & Título & Ano \\
\hline 01 & $\begin{array}{l}\text { ARENAS, M.L.M.; DÍAZ, } \\
\text { M.A.R.; MARTÍNEZ-PÉREZ, } \\
\text { L.F. }\end{array}$ & $\begin{array}{c}\text { Competencias ambientales em básica } \\
\text { primaria a partir del desarrollo de uma } \\
\text { unidad didáctica sobre la controversia? } \\
\text { vivienda o humedales? }\end{array}$ & 2016 \\
\hline 02 & $\begin{array}{l}\text { BARBOSA, L.G.D.; LIMA, } \\
\text { M.E.C.C.; MACHADO, A.H. }\end{array}$ & $\begin{array}{c}\text { Controvérsias sobre o aquecimento } \\
\text { global: circulação de vozes e de sentidos } \\
\text { produzidos em sala de aula. }\end{array}$ & 2012 \\
\hline 03 & $\begin{array}{l}\text { BERNARDO, J.R.R.; VIANNA, } \\
\text { D.M.; SILVA, V.H.D. }\end{array}$ & $\begin{array}{l}\text { Introduzindo questões sociocientíficas na } \\
\text { sala de aula: um estudo de caso } \\
\text { envolvendo produção de energia elétrica, } \\
\text { desenvolvimento e meio ambiente }\end{array}$ & 2011 \\
\hline 04 & $\begin{array}{l}\text { CARVALHO, L.M.; LEITE, } \\
\text { S.Q.M. }\end{array}$ & $\begin{array}{c}\text { Educação em Ciências para a vida: } \\
\text { construção de documentários baseados } \\
\text { em temas sociocientíficos da cidade }\end{array}$ & 2015 \\
\hline 05 & CULPI, V.L.F.L.; ALVES, J.A.P. & $\begin{array}{c}\text { Inserção do tema pegada hídrica no } \\
\text { ensino de Ciências: Percepções e } \\
\text { perspectivas de mudanças a partir da sala } \\
\text { de aula }\end{array}$ & 2015 \\
\hline 06 & $\begin{array}{l}\text { EGGERT, S.; NITSCH, A.; } \\
\text { BOONE, W.J. et al. }\end{array}$ & $\begin{array}{c}\text { Supporting Students' Learning and } \\
\text { Socioscientific Reasoning About Climate } \\
\text { Change - the Effect of Computer-Based } \\
\text { Concept Mapping Scaffolds }\end{array}$ & $\begin{array}{c}2017 \\
{[2016]}\end{array}$ \\
\hline 07 & $\begin{array}{l}\text { FATARELI, E.F.; FERREIRA, } \\
\text { L.N.A.; QUEIROZ, S.L. }\end{array}$ & $\begin{array}{c}\text { Argumentação no ensino de química a } \\
\text { partir do debate de questões } \\
\text { sóciocientíficas. }\end{array}$ & 2011 \\
\hline 08 & FEIERABEND, T.; EILKS, I. & $\begin{array}{l}\text { Raising students' perception of the } \\
\text { relevance of science teaching and } \\
\text { promoting communication and evaluation } \\
\text { capabilities using authentic and } \\
\text { controversial socio-scientific issues in the } \\
\text { Framework of climate changes. }\end{array}$ & 2010 \\
\hline 09 & $\begin{array}{l}\text { FERREIRA, A.C.; QUADROS, } \\
\text { A.L.; RODRIGUES, V.A.B. }\end{array}$ & $\begin{array}{l}\text { Ensino a partir de temas: é favorecida a } \\
\text { apropriação de conceitos científicos? }\end{array}$ & 2016 \\
\hline 10 & FREITAS, R.O.; BRAGA, M. & $\begin{array}{l}\text { Uma controvérsia sócio-científica em } \\
\text { escolas do Rio de Janeiro: relatos de um } \\
\text { fracasso. }\end{array}$ & 2010 \\
\hline 11 & $\begin{array}{l}\text { HOEG, D.; LEMELIN, N.; } \\
\text { BENCZE, J.L. }\end{array}$ & $\begin{array}{c}\text { Sociopolitical development of private } \\
\text { school children mobilising for } \\
\text { disadvantaged others. }\end{array}$ & 2015 \\
\hline 12 & IDELAND, M.; MALMBERG, C. & $\begin{array}{l}\text { Body talk: students' identity construction } \\
\text { while discussing a socioscentific issue. }\end{array}$ & 2012 \\
\hline 13 & $\begin{array}{l}\text { JONES, A.; BUNTTING, C.; } \\
\text { HIPKINS, R. et al. }\end{array}$ & $\begin{array}{l}\text { Developing Students' Futures Thinking in } \\
\text { Science Education. }\end{array}$ & 2012 \\
\hline 14 & LIMA, A.T.F.; SILVA, H.C. & $\begin{array}{c}\text { O funcionamento de diferentes } \\
\text { textualizações de discursos sobre um } \\
\text { mesmo tema sociocientífico em sala de } \\
\text { aula }\end{array}$ & 2011 \\
\hline 15 & $\begin{array}{l}\text { MARTÍNEZ, L.V.S.; } \\
\text { NAVARRO, Y.A.P.; } \\
\text { MARTÍNEZ-PÉREZ, L.F. }\end{array}$ & $\begin{array}{l}\text { La interdisciplinariedad em las cuestiones } \\
\text { sociocientíficas. }\end{array}$ & 2012 \\
\hline 16 & $\begin{array}{l}\text { MELO, L.M.; PRÍMOLA, N.S.; } \\
\text { MACHADO, P.F.L. }\end{array}$ & $\begin{array}{c}\text { E-lixo: um tema sociocientífico para aulas } \\
\text { de Química com enfoque CTS na } \\
\text { educação politécnica. }\end{array}$ & 2013 \\
\hline 17 & MOREIRA, M.C.A.; AMOR, R. & $\begin{array}{c}\text { Estudo comparativo da sustentabilidade } \\
\text { na visão de estudantes em eventos } \\
\text { esportivos em Londres e no Rio de } \\
\text { Janeiro. }\end{array}$ & 2015 \\
\hline 18 & MUNDIM, J.V.; SANTOS, & Ensino de ciências no ensino fundamental & 2012 \\
\hline
\end{tabular}




\begin{tabular}{|c|c|c|c|}
\hline & W.L.P. & $\begin{array}{l}\text { por meio de temas sociocientíficos: } \\
\text { análise de uma prática pedagógica com } \\
\text { vista à superação do ensino disciplinar. }\end{array}$ & \\
\hline 19 & $\begin{array}{l}\text { NICOLAOU, C.T.; EVAGOROU, } \\
\text { M.; LYMBOURIDOU, C. }\end{array}$ & $\begin{array}{c}\text { Elementary School Students' Emotions } \\
\text { when Exploring na Authentic Socio- } \\
\text { Scientific Issue through the Use of } \\
\text { Models. }\end{array}$ & 2015 \\
\hline 20 & $\begin{array}{l}\text { PARASKEVA-HADJICHAMBI, } \\
\text { D.; HADJICHAMBIS, A.C.; } \\
\text { KORFIATIS, K. }\end{array}$ & $\begin{array}{c}\text { How Students' Values are Intertwined } \\
\text { with Decisions in a Socio-scientific Issue. }\end{array}$ & 2015 \\
\hline 21 & $\begin{array}{l}\text { PEREIRA, R.G.; TRIVELATO, } \\
\text { S.L.F. }\end{array}$ & $\begin{array}{l}\text { Estudantes do ensino médio utilizam } \\
\text { conhecimento científico em seus } \\
\text { posicionamentos acerca de questões } \\
\text { sócio-científicas? }\end{array}$ & 2011 \\
\hline 22 & $\begin{array}{l}\text { PEREIRA, R.G.; TRIVELATO, } \\
\text { S.L.F. }\end{array}$ & $\begin{array}{c}\text { Uma análise sobre as características de } \\
\text { argumentos de alunos do Ensino Médio } \\
\text { sobre temática sócio-científica }\end{array}$ & 2009 \\
\hline 23 & POSADA, J.F.P.; GARCÍA, J.J.G. & $\begin{array}{l}\text { Una didáctica para el estudio del benceno } \\
\text { en productos de consumo masivo: } \\
\text { aprendizaje con participación ciudadana. }\end{array}$ & 2016 \\
\hline 24 & $\begin{array}{l}\text { RAMÍREZ, N.K.G.; MARTÍNEZ- } \\
\text { PÉREZ, L.F. }\end{array}$ & $\begin{array}{c}\text { Incidencia del abordaje de una cuestión } \\
\text { socio-científica em la alfabetización } \\
\text { científica y tecnológica de jóvenes y } \\
\text { adultos. }\end{array}$ & 2015 \\
\hline 25 & $\begin{array}{l}\text { SANTOS, C.G.M.M.; KATO, } \\
\text { D.S. }\end{array}$ & $\begin{array}{l}\text { Limites e possibilidades do uso de } \\
\text { situações problemas como recurso } \\
\text { pedagógico: os temas controversos sócio } \\
\text { científicos e as relações CTSA como } \\
\text { perspectivas para o Ensino de Ciências.- }\end{array}$ & 2013 \\
\hline 26 & $\begin{array}{l}\text { SANTOS, J.C.; CONRADO, } \\
\text { D.M.; NUNES-NETO, N.F. }\end{array}$ & $\begin{array}{l}\text { Questões sociocientíficas no ensino } \\
\text { fundamental de ciências: uma experiência } \\
\text { com poluição de águas. }\end{array}$ & 2016 \\
\hline 27 & $\begin{array}{l}\text { SANTOS, M.S.; AMARAL, } \\
\text { C.L.C.; MACIEL, M.D. }\end{array}$ & $\begin{array}{c}\text { Tema sociocientífico "cachaça" em aulas } \\
\text { práticas de química na educação } \\
\text { profissional: uma abordagem CTS. }\end{array}$ & 2012 \\
\hline 28 & SCHIMIDT, D.T.; SUTIL, N. & $\begin{array}{c}\text { O jogo digital Minecraft como um espaço } \\
\text { de discussão, reflexão e ação a partir dos } \\
\text { pressupostos da educação CTSA. }\end{array}$ & 2016 \\
\hline 29 & $\begin{array}{l}\text { SILVA, F.L.; PESSANHA, P.R.; } \\
\text { BOUHID, R. }\end{array}$ & $\begin{array}{c}\text { Abordagem do tema controverso } \\
\text { Radioatividade/Energia Nuclear em sala } \\
\text { de aula no Ensino Médio - Um Estudo de } \\
\text { Caso }\end{array}$ & 2011 \\
\hline 30 & SILVA, V.F.; BASTOS, F. & $\begin{array}{l}\text { Abordagem interdisciplinar de questões } \\
\text { sóciocientíficas: a contribuição de um } \\
\text { projeto didático sobre a dengue para a } \\
\text { formação inicial de professores.- }\end{array}$ & 2011 \\
\hline 31 & $\begin{array}{l}\text { VALE, W.K.M.; SOUZA, S.R.; } \\
\text { FIRME, R.N. }\end{array}$ & $\begin{array}{l}\text { Investigando questões sociocientíficas } \\
\text { na temática Combustíveis fósseis e } \\
\text { alternativos: em quais contextos são } \\
\text { discutidas as relações CTS. }\end{array}$ & 2015 \\
\hline 32 & $\begin{array}{l}\text { VISSICARO, S.P.; FIGUEIRÔA, } \\
\text { S.F.M.; ARAÚJO, M.S. }\end{array}$ & $\begin{array}{l}\text { Questões sociocientíficas nos anos } \\
\text { iniciais do Ensino Fundamental: o tema } \\
\text { água em evidência. }\end{array}$ & 2016 \\
\hline 33 & WU, Y.T.; TSAI, C.C. & $\begin{array}{l}\text { The Effects of Different On-line } \\
\text { Searching Activities on High School } \\
\text { Students' Cognitive Structures and } \\
\text { Informal Reasoning Regarding a Socio- } \\
\text { scientific Issue. }\end{array}$ & 2011 \\
\hline 34 & $\begin{array}{l}\text { ZEIDLER, D.L.; SADLER, T.D.; } \\
\text { APPLEBAUM, S. et al. }\end{array}$ & $\begin{array}{l}\text { Advancing Reflective Judgment through } \\
\text { Socioscientific Issues. }\end{array}$ & 2009 \\
\hline
\end{tabular}

Fonte: Elaborado pelos autores. 
A análise descritiva do corpus da pesquisa mostrou um maior número de publicações de propostas entre os anos de 2009 e 2015. Importantes publicações da área foram lançadas precedendo esse período, como o trabalho de Ratcliffe e Grace (2003), Hodson (2004), Sadler (2004a; b), Zeidler et al. (2005), Zeidler e Nichols (2009). Estes estudos podem ter influenciado a comunidade de pesquisadores da área a desenvolverem, aplicarem e publicarem suas pesquisas acerca do uso de Questões Sociocientíficas em contextos educacionais, inclusive, sendo um ou mais destes autores citados em 56\% (19) dos trabalhos analisados.

Apesar de serem pesquisas que discutem Questões Sociocientíficas, 23 dos 34 trabalhos analisados não trazem explicitamente um conceito do que entendem do termo QSC. Destes 23 trabalhos, dez (trabalhos 3,6,10,11,12,13,16,21,22,34) discutem QSC sem mencionar algum conceito ou características, e seis (Quadro 2) apenas colocam, de um modo geral e difuso, algumas ideias relacionadas à QSC; por exemplo, uso de QSC para contextualizar um problema socialmente relevante. Ou seja, em trabalhos que se propuseram investigar temáticas ligadas às QSC, muitos autores não esclarecem a compreensão que eles atribuem sobre esse termo. Isto pode ser problemático, pois, como discutido por Conrado (2017), em sua tese, arcabouços teóricos, acerca do uso de QSC no Ensino de Ciências, são importantes para explicitar pressupostos que orientam os trabalhos, assim como para indicar a coerência entre fundamentos, meios e objetivos do ensino de ciências utilizando QSC. Logo, a explicitação de uma base teórica sólida é importante para evitar análises superficiais e/ou equívocos nas discussões realizadas; ou seja, mesmo que os autores não utilizem a QSC como principal objeto de estudo, a vinculação teórica precisa estar indicada, inclusive como forma de melhor qualificar/sustentar os argumentos elaborados. 
Quadro 2 - Artigos analisados que não explicitam um conceito para QSC.

\begin{tabular}{|c|c|c|}
\hline Código & $\begin{array}{l}\text { Ideias no texto } \\
\text { associadas à QSC }\end{array}$ & Fragmento de texto \\
\hline 05 & $\begin{array}{l}\text { Contextualização } \\
\text { social de questão atual } \\
\text { relevante. }\end{array}$ & $\begin{array}{c}\text { "...estudos sobre a importância da contextualização e da inserção dos } \\
\text { assuntos ambientais no cotidiano escolar..." (p.21) } \\
\text { “...a necessidade da contextualização e ampliação do } \\
\text { tema "Água"..." (p.22). }\end{array}$ \\
\hline 07 & $\begin{array}{c}\text { Fomentar debates para } \\
\text { aprendizado } \\
\text { significativo. } \\
\text { Temas que } \\
\text { possibilitam o } \\
\text { desenvolvimento de } \\
\text { habilidades de } \\
\text { argumentação. }\end{array}$ & $\begin{array}{l}\text { "A estratégia de aprendizagem baseada em debates tem sido apontada } \\
\text { como vantajosa a educadores e alunos, na medida em que atende ao } \\
\text { conjunto de posturas e ações educativas para um aprendizado } \\
\text { significativo das ciências (...) discussões sobre temáticas científicas, } \\
\text { sociais, ambientais, políticas e econômicas pode vir a aprimorar a } \\
\text { capacidade argumentativa dos alunos..." (p.2). }\end{array}$ \\
\hline 09 & $\begin{array}{l}\text { Problematização de } \\
\text { questões socialmente } \\
\text { relevantes }\end{array}$ & $\begin{array}{l}\text { "Nessa abordagem, o ensino ocorre por meio da problematização de } \\
\text { questões sociais relevantes..." (p.1099). }\end{array}$ \\
\hline 14 & $\begin{array}{l}\text { Educação socialmente } \\
\text { contextualizada. }\end{array}$ & $\begin{array}{l}\text { "...formação de sujeitos que participem da dinâmica dos sentidos da } \\
\text { ciência num contexto mais amplo de compreensões, significações e } \\
\text { posicionamentos implicados em questões mais relacionadas à sua vida..." } \\
\text { (p.2). "...."atores" e "vozes" envolvidos nessas controvérsias, os } \\
\text { argumentos e contra-argumentos, ajudando a formar um quadro amplo e } \\
\text { contextual, no sentido social e político, onde aparecem os conhecimentos } \\
\text { científicos associados a esse tema" (p.3). }\end{array}$ \\
\hline 29 & $\begin{array}{l}\text { Contextualização de } \\
\text { um tema científico em } \\
\text { seus múltiplos } \\
\text { aspectos }\end{array}$ & $\begin{array}{l}\text { "As implicações desse tema na ciência, na tecnologia e na sociedade } \\
\text { geram controvérsias que envolvem diversas dimensões: científica, } \\
\text { tecnológica, social, ambiental, econômica e política" (p.5). }\end{array}$ \\
\hline 30 & $\begin{array}{c}\text { Abordagem } \\
\text { interdisciplinar de } \\
\text { questão atual } \\
\text { relevante. } \\
\text { Aprendizagem } \\
\text { significativa sobre o } \\
\text { conhecimento } \\
\text { científico. }\end{array}$ & $\begin{array}{l}\text { “...as disciplinas de Ciências e de Língua Portuguesa em uma } \\
\text { perspectiva de trabalho interdisciplinar, a partir de uma questão sócio- } \\
\text { científica de relevância na atualidade: o caso da dengue" (p.3). } \\
\text { “...percebemos que o Projeto Didático sobre a dengue poderia contribuir } \\
\text { para uma aprendizagem significativa sobre o assunto" (p.4). }\end{array}$ \\
\hline
\end{tabular}

Fonte: Elaborado pelos autores.

Dentre os 11 trabalhos analisados que conceituam explicitamente o termo QSC (Quadro 3), podemos perceber que sete desses trabalhos conceituam a QSC como um problema ou dilema controverso, aliado a aspectos sociais, enquanto quatro trabalhos indicam que as QSC são temas ou questões sociais associadas à C\&T. Nesse sentido, há uma certa concordância, entre os autores, quanto à definição que utilizaram, sobretudo por serem baseadas na literatura da área, utilizando trabalhos de autores como "Dana L. Zeidler", "Derek Hodson", "Leonardo Fabio Martínez Pérez", "María Pilar Jimenez-Aleixandre", "Mary Ratcliffe", "Pedro Guilherme Rocha dos Reis", "Stein Dankert Kolstø", "Troy D. Sadler" e "Wildson Luiz Pereira dos Santos". 
Quadro 3 - Artigos analisados que explicitam um conceito para QSC.

\begin{tabular}{|c|c|c|}
\hline Código & Conceito de QSC & Fragmento do texto \\
\hline 01 & $\begin{array}{l}\text { Controvérsia de interesse } \\
\text { público, sem solução } \\
\text { definitiva e única, que } \\
\text { envolve diversos fatores }\end{array}$ & $\begin{array}{l}\text { "Las CSC son problemas abiertos sin soluciones definitivas; } \\
\text { inclusive tienden a tener variadas soluciones; estos problemas están } \\
\text { vinculados con hechos controvertidos de interés público e } \\
\text { influenciados por diversos factores de la política, la economía y la } \\
\text { ética (Sadler, 2011)" (p.708). }\end{array}$ \\
\hline 15 & $\begin{array}{l}\text { Temas que explicitam } \\
\text { aspectos socioculturais do } \\
\text { conhecimento científico, } \\
\text { relacionando aspectos de } \\
\text { CTS }\end{array}$ & $\begin{array}{l}\text { "Son asuntos en los cuales se hace más explícita la naturaleza } \\
\text { sociocultural del conocimiento científico (interdisciplinariedad del } \\
\text { conocimiento) y la mutua relación ciencia, tecnología y sociedad" } \\
\text { (p.156). }\end{array}$ \\
\hline 18 & $\begin{array}{l}\text { Questões de grande impacto } \\
\text { social, relacionadas à C\&T }\end{array}$ & $\begin{array}{l}\text { "Os temas de natureza CTS, também denominados temas socio- } \\
\text { científicos (SANTOS; MORTIMER, 2009), envolvem questões } \\
\text { referentes à ciência e tecnologia que têm grande impacto na } \\
\text { sociedade" (p.790-791). }\end{array}$ \\
\hline 19 & $\begin{array}{l}\text { Problemas sociais } \\
\text { controversos, pouco } \\
\text { estruturados, influenciados } \\
\text { pela ciência, mas que } \\
\text { precisam ser integrados com } \\
\text { questões éticas }\end{array}$ & $\begin{array}{l}\text { "SSI can be defined as those issues which represent social concerns } \\
\text { and problems that are conceptually influenced by science and } \\
\text { require the integration of science concepts and processes with } \\
\text { issues of moral, ethics, costs and values (Sadler, Barab, \& Scott, } \\
\text { 2007; Zeidler \& Sadler, 2007). SSI are by nature, controversial and } \\
\text { ill-structured (Zeidler \& Sadler, 2007)" (p.242-243). }\end{array}$ \\
\hline 20 & $\begin{array}{l}\text { Problemas complexos do } \\
\text { mundo real que envolvem } \\
\text { questões éticas e sociais, } \\
\text { são pouco definidas e sem } \\
\text { soluções absolutas }\end{array}$ & $\begin{array}{l}\text { "Socio-scientific issues are complex, controversial and ill- } \\
\text { structured real-world problems that involve social and ethical } \\
\text { considerations..." (p.494). } \\
\text { socio- scientific issues are ill-defined in nature, and there is no } \\
\text { absolute solution to these problems (...)" (p.497). }\end{array}$ \\
\hline 23 & $\begin{array}{l}\text { Dilema social complexo } \\
\text { relacionado com a ciência. } \\
\text { Questão social controversa } \\
\text { associada com conceitos e } \\
\text { procedimentos da ciência. }\end{array}$ & $\begin{array}{l}\text { "Las cuestiones socio-científicas (CSC), representan un dilema } \\
\text { social complejo basado en la aplicación de la ciencia y su práctica. } \\
\text { Las CSC son cuestiones sociales controversiales con nexos } \\
\text { conceptuales y/o procedimentales con la ciencia; son polémicas, } \\
\text { abiertas, y formadas por problemas sin soluciones simples y } \\
\text { directas (Sadler \& Fowler, 2006)" (p.1251). }\end{array}$ \\
\hline 24 & $\begin{array}{l}\text { Problemas controversos e } \\
\text { complexos, relevantes e } \\
\text { abertos e que suscitam } \\
\text { diferentes posicionamentos } \\
\text { da sociedade }\end{array}$ & $\begin{array}{l}\text { "Las CSC son problemas abiertos, complejos y controvertidos, } \\
\text { muchos de ellos sin respuestas definitivas, frente a los cuales se } \\
\text { encuentran muchas posturas sociales a favor o en contra; lo cual } \\
\text { denota su relevancia a medida que transcurre el tiempo y aumentan } \\
\text { los avances de la ciencia y los problemas ambientales" (p.95). }\end{array}$ \\
\hline 25 & $\begin{array}{c}\text { Temas vinculados às } \\
\text { dimensões éticas presentes } \\
\text { nas opiniões dos estudantes }\end{array}$ & $\begin{array}{c}\text { "Segundo Levinson (2001) os temas controversos sociocientíficos } \\
\text { trazem dimensões éticas, morais e valores atrelados às opiniões dos } \\
\text { estudantes" (p.6). }\end{array}$ \\
\hline 31 & $\begin{array}{l}\text { Questões ambientais, } \\
\text { políticas, econômicas, } \\
\text { éticas, sociais e culturais } \\
\text { relacionadas à C\&T }\end{array}$ & $\begin{array}{l}\text { "[...] entendidas como questões ambientais, políticas, econômicas, } \\
\text { éticas, sociais e culturais relativas à ciência e à tecnologia" (p.2). }\end{array}$ \\
\hline 32 & $\begin{array}{l}\text { Controvérsias sociais que } \\
\text { estimulam participação dos } \\
\text { estudantes e envolvem } \\
\text { discussões entre CTS }\end{array}$ & $\begin{array}{l}\text { "...são aquelas que abrangem assuntos sociais controversos, ... que } \\
\text { são frequentemente abordados pelos meios de comunicação, e que } \\
\text { estimulam a participação do estudante nas discussões decorrentes } \\
\text { da interação entre ciência - tecnologia - sociedade" (p.1597-1598). }\end{array}$ \\
\hline 33 & $\begin{array}{c}\text { Dilemas sociais } \\
\text { relacionados } \\
\text { conceitualmente ou } \\
\text { tecnologicamente com a } \\
\text { ciência }\end{array}$ & $\begin{array}{l}\text { "...some social dilemmas with conceptual or technological } \\
\text { associations with science (often termed "socio-scientific issues")..." } \\
\text { (p.772). }\end{array}$ \\
\hline
\end{tabular}

Fonte: Elaborado pelos autores.

Adicionalmente, os trabalhos $02,04,08,17,26,27,28$ não enunciaram explicitamente a definição de QSC, mas caracterizaram o termo, com base na literatura da área. 
Dificuldades e limitações do ensino baseado em QSC

Durante as aplicações de suas propostas didáticas, alguns dos autores se depararam com situações e aspectos do uso de QSC tidas, por eles, como limitantes, dificultando o desenvolvimento de uma prática pedagógica baseada em questões sociocientíficas. A partir da análise realizada, identificamos quatro problemáticas principais (Gráfico 1) e as discutiremos a seguir.

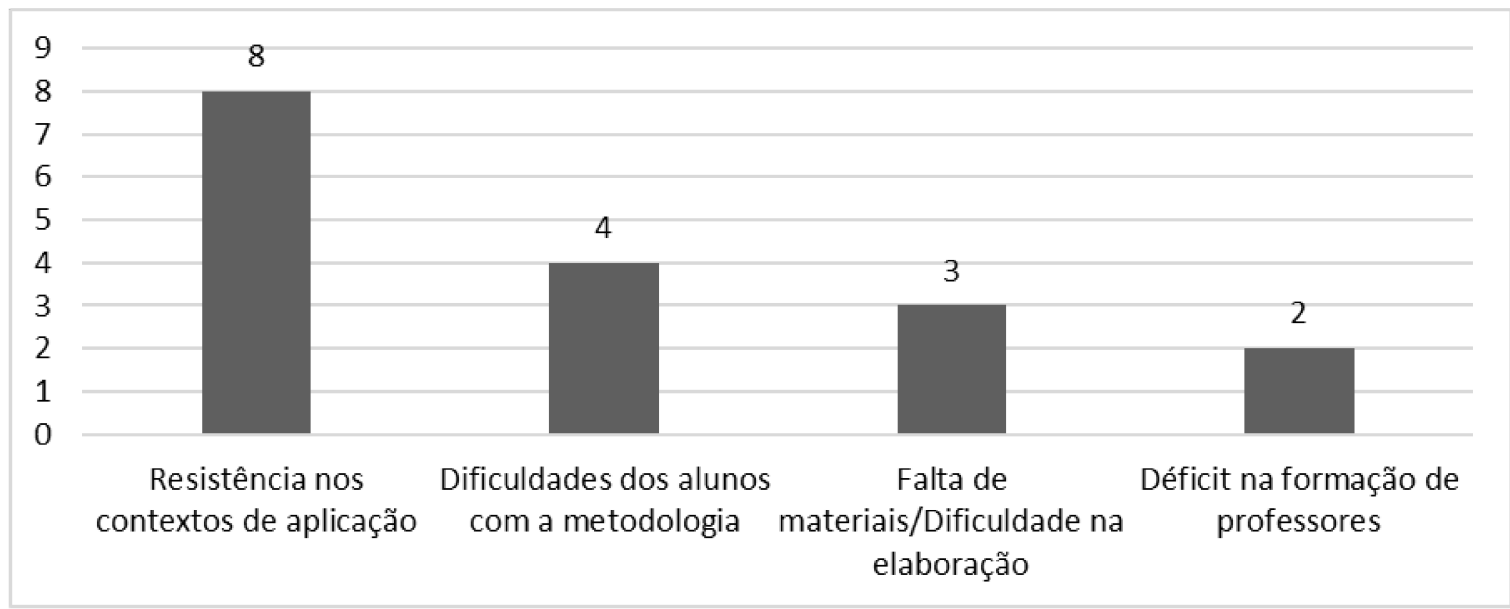

Gráfico 1 - Frequência das dificuldades/limitações apontadas pelos autores.

Fonte: Elaborado pelos autores.

A primeira dificuldade está na resistência de professores, gestores e instituições em utilizar as QSC para abordar os conteúdos (trabalhos 2,10,11,12,19,25,27,28). Para Santos e Kato (2013), as propostas de ensino baseadas em QSC, para que atinjam resultados mais satisfatórios, exigem certo nível de robustez durante sua elaboração (no que diz respeito à elaboração, ao planejamento e à adequação da proposta ao contexto da sala de aula onde será realizada), o que acaba por aumentar a resistência dos professores na utilização das mesmas. Freitas e Braga (2010) acrescentam ainda que o próprio caráter interdisciplinar ${ }^{3}$ das QSC, por vezes, pode exigir um trabalho conjunto dos professores; algo que poderia ser muito positivo para o ensino e o aprendizado dos estudantes, mas que acaba por ser problemático quando pensamos em uma estrutura escolar disciplinar, na qual professores fazem planejamentos individuais tentando cumprir as imensas listas de conteúdos previstos nos currículos escolares.

Para nós, esses problemas ocorrem, também, por uma falta de melhor reflexão e planejamento no processo de seleção dos conteúdos, visto que esse excesso de conteúdo (principalmente os conceituais) se faz presente não só nos currículos, mas, também, nos materiais educativos, como os livros didáticos (DAL-FARRA; NUNES-NETO, 2014) e,

\footnotetext{
${ }^{3}$ Apesar de que, para nós, as QSC possuem um caráter transdisciplinar, conforme discutido anteriormente, mantivemos o termo "interdisciplinar" aqui, por este ter sido o termo utilizado pelos autores do trabalho analisado. Porém, este é um indicativo de que este ponto da natureza das QSC (se inter ou transdisciplinar) ainda é algo não consolidado na literatura.
} 
poderiam ser atenuados se os professores partissem, por exemplo, de conceitos estruturantes (sensu GAGLIARDI, 1986) ao planejarem suas aulas; ademais, alguns professores, por questões ideológicas ou por estarem em situações de conflito, acham melhor não se posicionarem em momentos como estes. Utilizar questões sociocientíficas exige uma série de habilidades dos professores, além de demandar tempo não só para o preparo (algo escasso se considerarmos que alguns professores trabalham até $60 \mathrm{~h}$ semanais em turmas superlotadas), mas, também, tempo em sala de aula para o desenvolvimento das atividades, como apontado por Santos et al. (2012) e Schimidt e Sutil (2016).

Ademais, Hoeg et al. (2015) afirmam que as instituições de ensino, em especial as de cunho privado, mais preocupadas com os conteúdos conceituais, o preparo de estudantes para exames admissionais e o cumprimento de módulos e apostilas, apresentam também forte resistência para que seus professores inovem com práticas que possam "atrasar" os apertados cronogramas esperados. Há também, segundo Barbosa et al. (2012), para se inserir as QSC em sala de aula, a necessidade da institucionalização, por meio do currículo, de um ensino voltado para a formação política.

Para Ideland e Malmberg (2012), o próprio prestígio dado à ciência, e que o mercado educacional faz uso ao tratar o conhecimento (científico) como uma mercadoria, limita o uso de QSC, pois utilizar as controvérsias socioambientais auxilia na quebra da visão distorcida da ciência ${ }^{4}$ como infalível e capaz de resolver todos os problemas, o que resultaria em um prejuízo para o mercado educacional.

O trabalho envolvendo as QSC (não-finalizadas e sem necessariamente possuir uma solução fechada), ao desconstruir o prestígio dado à ciência, em especial à visão deturpada da ciência exata e superior, pode acarretar uma resposta de carga emotiva negativa nos alunos. Tal resposta prejudicaria o aprendizado dos mesmos, conforme apontado por Nicolaou et al. (2015), visto que, ao desconstruir essa visão de uma ciência finalizada e pronta (que muitas vezes é apresentada no Ensino de Ciências), acaba por inserir naqueles contextos uma, segundo os autores, “incerteza" (NICOLAOU et al., 2015, p. 255, tradução nossa), em especial, quanto ao valor do conhecimento científico.

Segundo os mesmos autores, principalmente os alunos mais jovens teriam dificuldade em lidar com tais "incertezas", pela falta de maturidade e desenvolvimento emocional. Entretanto, torna-se necessário explicitar e discutir esses aspectos, na medida em que estes são os momentos nos quais a dimensão atitudinal e afetiva dos conteúdos pode ser melhor explorada no processo formativo dos estudantes, auxiliando, inclusive, em seu crescimento e

\footnotetext{
${ }^{4}$ Entendemos como visões distorcidas da Ciência a concepção empírico indutivista e ateórica; o papel "neutro" da observação e da experimentação (não influenciadas por ideias apriorísticas); a visão rígida (exata, infalível etc.); a visão aproblemática e ahistórica (portanto, dogmática e fechada) da Ciência; a visão acumulativa de crescimento linear dos conhecimentos científicos (ver GIL-PÉREZ et al., 2001; PRAIA et al., 2002).
} 
amadurecimento emocional para lidar com situações sobre as quais não temos total controle dos fatores envolvidos. Ademais, vivemos um período em que os jovens estão cada vez mais inseridos em uma sociedade incerta, fluida, líquida; logo, tais incertezas fazem parte do cotidiano dos mesmos, principalmente frente às problemáticas socioambientais, como as QSC, presentes no dia-a-dia dos mesmos. Inserir tais contextos nos momentos de ensino e aprendizagem torna-se de relevada importância, pois "incertezas" não devem ser vistas a partir de uma ótica negativa, mas, sim, como uma possibilidade de trabalhar com os estudantes valores, como comprometimento, engajamento e empoderamento, objetivos viabilizados a partir do ensino baseado em QSC.

Outro fator limitante encontrado no uso de questões sociocientíficas em propostas didáticas está associado com a dificuldade dos discentes ao se depararem com tal metodologia (trabalhos 10,19,25,33). Isso porque o trabalho envolvendo QSC demanda uma maior capacidade argumentativa, tal qual discutido por Freitas e Braga (2010), Wu e Tsai (2011) e Nicolaou et al. (2015), que afirmam que ele exige maior scaffolding ${ }^{5}$ e preparação dos alunos. Ademais, para Freitas e Braga (2010), nem sempre os alunos estão cientes/informados das controvérsias socioambientais tratadas, restringindo, dessa forma, sua participação durante as atividades:

Rapidamente o professor percebeu que os alunos não estavam informados sobre os temas ou possuíam um conhecimento superficial. O caso da descoberta e exploração de grandes poços de petróleo na camada pré-sal na costa brasileira ilustra bem isto.

Todos os alunos já tinham ouvido falar sobre esse tema, pois a imprensa já havia divulgado bastante. Mas poucos realmente sabiam do que se tratava e da importância disso para o Brasil (FREITAS; BRAGA, 2010, p.5, grifo nosso).

Ainda, para os mesmos autores, todo esse cenário acaba por ser reforçado pelos próprios sistemas educacionais existentes, que não estimulam os alunos a participarem ativamente dos seus processos de aprendizagem. Santos e Kato (2013) reforçam, também, que o ensino baseado em QSC, devido ao seu caráter "ill-structured", pode desencadear emoções negativas nos estudantes, o que contribuiria negativamente para o seu aprendizado, "[...] pois, quando envolve a crença, a cultura, os valores e a ética, e a religião, fica difícil confrontar sua opinião, pois, envolve a fé. Cria-se, então, um obstáculo para solucionar o problema" (SANTOS; KATO, 2013, p.7, grifo nosso). Deste modo, vemos, então, a importância do caráter transdisciplinar do ensino baseado em QSC, visto que possibilita um aprendizado integrado dos conteúdos científicos com outros tipos de conhecimentos e outras formas de

\footnotetext{
${ }^{5}$ Scaffolding, em português, pode ser traduzido como "colocar andaimes", ou seja, suportes que permitam alcançar níveis mais elevados. O termo é, então, utilizado pela literatura pois refere-se justamente ao fato do mediador/professor/tutor dar aos estudantes suportes/auxílios para que eles avancem nas atividades propostas.

${ }^{6}$ Ill-structured problems, em tradução livre "problemas mal-estruturados", podem ser entendidos como situaçõesproblema em que os elementos da problemática envolvida não estão totalmente explícitos, bem como os reais objetivos da atividade não ficam necessariamente apresentados para os estudantes, exigindo que os alunos façam julgamentos e se posicionem acerca de suas decisões.
} 
comunicação, o que demanda dos estudantes conhecer e praticar virtudes tanto epistêmicas quanto morais, além de considerar o posicionamento de sujeitos de outros grupos sociais. Ademais, para que o trabalho utilizando essas controvérsias se dê de uma forma que possibilite aos estudantes uma melhor experiência de aprendizado, as QSC precisam ser aplicadas dentro de modelos teóricos, alguns já disponíveis na literatura, como a estratégia das cinco fases (CONRADO, 2017), ao invés de apenas serem incluídas no planejamento pedagógico, sem estarem de fato alinhadas com os objetivos educacionais consonantes com o ensino baseado em QSC.

A terceira problemática apontada nos trabalhos é a falta de materiais educativos, bem como a dificuldade em elaborá-los (trabalhos de 09,22,32). Para Vissicaro et al. (2016), os materiais utilizados em sala precisam ser elaborados, levando em consideração que as fontes sejam confiáveis, de fácil compreensão pelos alunos e que se adequem ao tempo disponível para a aula. Além disso, segundo Pereira e Trivelato (2009), os materiais devem ser capazes de mobilizar/resgatar conteúdos trabalhados anteriormente no cronograma das disciplinas. Ferreira et al. (2016) trazem ainda que, quando não bem estruturadas, tais propostas de ensino podem ainda dificultar a mobilização do conhecimento científico no cotidiano dos alunos, não exigindo, por exemplo, o posicionamento deles sobre um fato político.

\begin{abstract}
Analisar os resultados em termos de apropriação de conceitos científicos a partir de um debate promovido em sala de aula trouxe dados que não corresponderam a nossa expectativa inicial. No entanto, eles nos mostram o quanto o mundo da Ciência ainda está distanciado do mundo real projetado pelos estudantes. Os conceitos científicos foram usados para responder uma questão proposta durante a prova, mas não foram usados para se posicionar em relação a um fato político/ambiental (FERREIRA et al., 2016, p.1111, grifo nosso).
\end{abstract}

A partir deste trecho, podemos, de certo modo, perceber a necessidade de elaborarmos materiais didáticos apropriados para o uso em propostas de ensino baseadas em QSC, bem como materiais instrucionais que auxiliem os docentes na condução das aulas sob essa perspectiva de ensino, pois é importante termos coerência entre os objetivos esperados e os métodos utilizados no ensino com QSC. Em outras palavras, faz-se necessário mais do que apenas materiais apropriados; precisamos desenvolver o planejamento didático considerando, sobretudo, os objetivos do ensino e da aprendizagem e as estratégias de ensino e de avaliação empregadas (CONRADO, 2017).

Ademais, também se faz necessário, desde a formação inicial dos professores, bem como nos momentos de formação continuada, que os docentes discutam e aprendam a elaborar e a lidar com a utilização de QSC como estruturadoras das atividades educativas para que possam tirar o maior e melhor proveito desta ferramenta. Inclusive, porque o uso de estratégias como QSC ainda é um dilema para vários professores, já que o questionamento da visão tradicional e distorcida da ciência (problematização comum nesta estratégia didática) 
acaba por fragilizar o prestígio dado à ciência e ao professor - que seria o detentor do conhecimento [científico] - causando certa insegurança entre os docentes; logo, utilizar as QSC demanda uma formação política e crítica dos docentes para que estejam preparados para lidar com essas situações (MARTÍNEZ-PÉREZ, 2012).

Outra limitação é a falta de discussões/preparo, tanto na formação inicial quanto na continuada dos professores para o uso de QSC (trabalhos 10,32). Freitas e Braga (2010), por exemplo, pontuam que muitos docentes não são preparados para conduzir situações de debate, em especial por não possuírem nenhum referencial sobre esta prática. Vissicaro et al. (2016) apontam também um distanciamento entre a academia e a realidade escolar, reforçando a lacuna existente entre a teoria e a prática durante a formação. Isso porque, se a formação docente ainda é baseada em métodos tradicionais e tecnicistas, os professores terão dificuldades em desenvolver sua prática educativa embasada em métodos inovadores ativos e participativos. A partir disso, vemos a necessidade da inclusão, na formação inicial e continuada de professores, de discussões que os preparem para utilizar outros encaminhamentos metodológicos, como as propostas didáticas norteadas por QSC.

Aqui vemos uma série de problemáticas que os autores dos trabalhos analisados apontam como relacionados à implementação das QSC como estratégia pedagógica, mas acreditamos que barreiras como a resistência de professores/gestores/instituições, a falta de materiais didáticos e instrucionais, o déficit na formação docente entre outros, estão relacionados a uma questão mais ampla, voltada à dificuldade e à resistência a métodos e modelos inovadores de ensino. Modelos progressistas de ensino, como a pedagogia libertadora proposta por Paulo Freire ou a pedagogia histórico-crítica de Demerval Saviani, por exemplo, encontram uma série de empecilhos, principalmente institucionais, em sua concretização em diversos espaços (ARANHA, 1996). Tais tendências pedagógicas, que buscam desenvolver um espírito crítico, reflexivo, libertador e empoderado nos estudantes, acabam encontrando situações de conflito em diversas instâncias, visto que estimulam os estudantes a pensarem criticamente o próprio sistema sociopolítico-econômico em que estão inseridos e que, geralmente, sustentam os sistemas de ensino atuais, mais voltados ainda a uma tendência tradicional tecnicista (LUCKESI, 1994).

É evidente que, ao nos propormos utilizar encaminhamentos metodológicos em sala de aula que busquem subverter um modelo tradicional-tecnicista (e. g. QSC, Aprendizagem Baseada em Problemas - ABP, Pedagogia de Projetos, Aprendizagem Baseada em Jogos etc.), encontraremos oposição de vários lados (escolas, professores, comunidade e até dos próprios alunos), mas devemos estar preparados "no sentido de estarmos comprometidos com a busca de uma educação que prometa tornar o mundo melhor, mais gentil e mais socialmente justo" (HODSON, 2013, p.329, tradução nossa). 
Vantagens e possibilidades advindas do ensino baseado em QSC

Apesar dessas dificuldades encontradas, é importante ressaltar que há uma série de possibilidades positivas advindas do uso de QSC levantadas pelos envolvidos nas propostas analisadas (Gráfico 2).

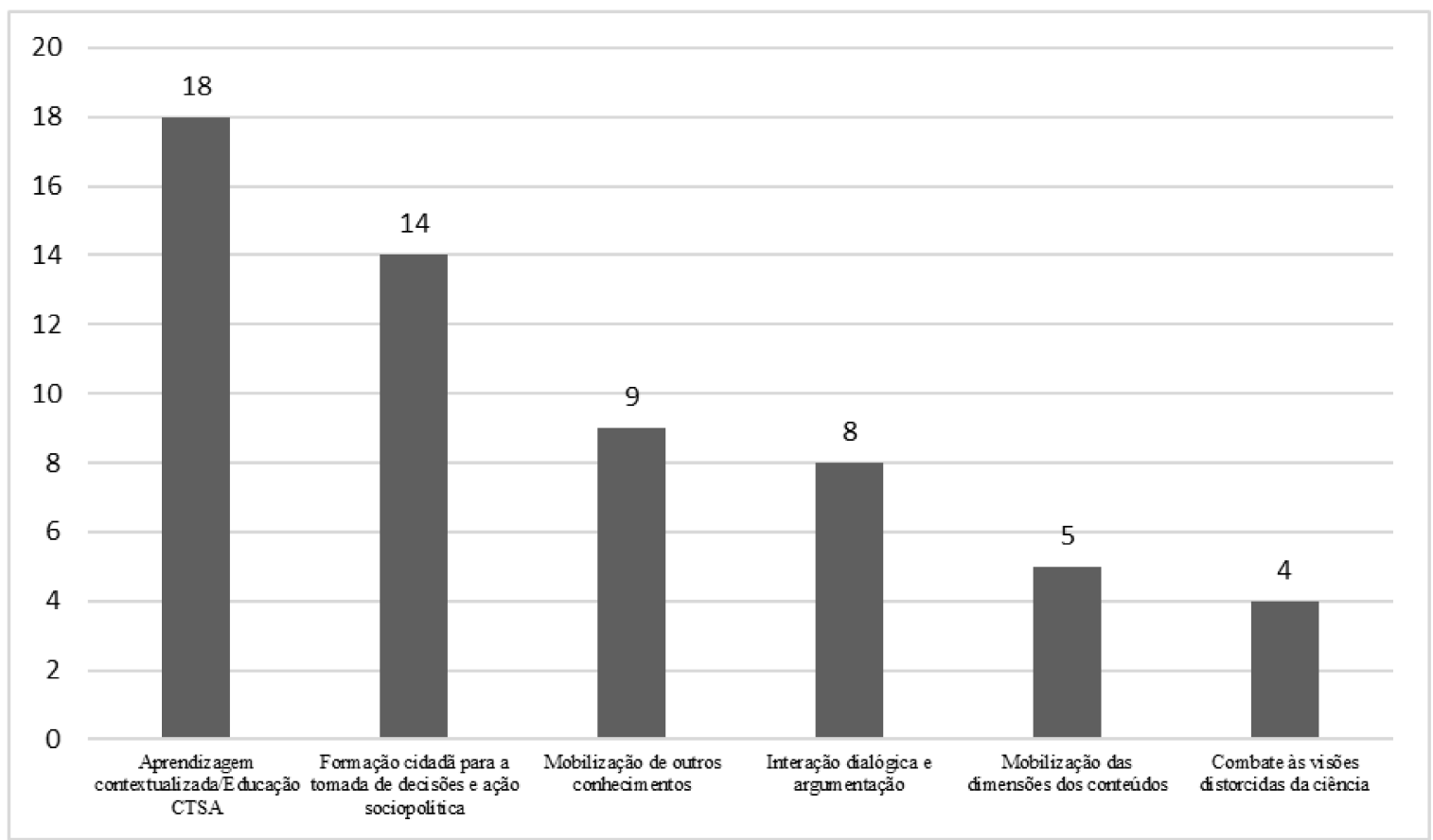

Gráfico 2 - Frequência das vantagens/possibilidades apontadas pelos autores.

Fonte: Elaborado pelos autores.

A aprendizagem contextualizada com a realidade dos alunos, de modo a esclarecer as ligações entre Ciência, Tecnologia, Sociedade e Ambiente (trabalhos: $01,02,03,04,08,11,13,16,18,19,23,24,25,26,29,33,34)$ é apontada como uma das principais vantagens do uso de tal metodologia, conforme autores de alguns dos trabalhos analisados. Zeidler et al. (2009) destacam, inclusive, que, a partir das questões sociocientíficas, os alunos têm melhores experiências no aprendizado de conceitos dos conteúdos científicos, principalmente por perceberem de forma mais evidente como as relações entre suas realidades e os conteúdos são traçados. Hoeg et al. (2015) afirmam que a contextualização se dá, inclusive, a partir não só da realidade dos estudantes, mas também de contextos sociais diferentes dos vivenciados por eles; o que, para Wu e Tsai (2011) e Nicolaou et al. (2015), possibilita que eles alcancem melhores resultados de aprendizagem. De acordo os trabalhos de Mundin e Santos (2012), Carvalho e Leite (2015) e Ramírez e Martínez-Perez (2015), as relações existentes entre as esferas Ciência, Tecnologia, Sociedade e Ambiente, abordagem de ensino da qual se originam as QSC, também se concretizam pedagogicamente a partir do uso das QSC; inclusive, devido a esse ensino de modo contextualizado, melhores resultados de aprendizagem e rendimento escolar são alcançados. 
O desenvolvimento da criticidade, voltado principalmente à formação cidadã, visando à tomada de decisões e ao engajamento em ações sociopolíticas (trabalhos 01,02,04,11,16,17,20,21,22,24,25,26,27,34) é outro resultado de destaque em um ensino baseado em questões sociocientíficas. Propõe-se que os discentes sejam estimulados a tomarem decisões de forma crítica frente aos impactos da ciência, conforme os trabalhos de Pereira e Trivelato (2009; 2011), Santos et al. (2012), Paraskeva-Hadjichambi et al. (2015) e Arenas et al. (2016), em especial àqueles impactos ligados aos contextos dos estudantes, como no trabalho de Santos et al. (2016), e, a partir disso, fomentar a responsividade dos alunos aos problemas sociocientíficos, alcançando uma formação cidadã mais madura, tal qual apontado por Barbosa et al. (2012), Santos e Kato (2013), Carvalho e Leite (2015), Moreira e Amor (2015), e Ramírez e Martínez-Pérez (2015). Deste modo, permite-se que eles consigam atuar tanto em nível individual quanto coletivo, assim como discutido por Zeidler et al. (2009), Melo et al. (2013), Hoeg et al. (2015) e Arenas et al. (2016).

A mobilização de outros saberes e/ou tipos de conhecimento (trabalhos 04,12,15,17,21,22,23,24,26), que não os científicos, também é possibilitada a partir do ensino baseado em QSC. Segundo Ideland e Malmberg (2012), o trabalho envolvendo QSC viabiliza o encontro de diversos discursos em situações que apresentam um cenário multifatorial (diferentes culturas, valores, normas). Pereira e Trivelato (2009; 2011), ao analisarem como os estudantes elaboram seus argumentos em discussões acerca da controvérsia envolvendo a Lei da Biossegurança (Lei n. ${ }^{\circ}$ 11.105/2005), perceberam que, no processo argumentativo, bem como na tomada de decisão, os alunos mobilizam, por muitas vezes, conhecimentos de outros campos que não o científico, sejam os ligados à ética, à economia ou ao direito, por exemplo. Outro trabalho que discutiu essa mobilização foi o realizado por Santos et al. (2016), ao abordarem conteúdos de ética ambiental de modo integrado ao ensino de Ciências nos anos do Ensino Fundamental.

Ao nosso ver, esta mobilização de outros conhecimentos, para além do científico, é uma potencialidade do uso de QSC, visto que o caráter transdisciplinar das controvérsias acaba por trazer esse resgate de outros saberes (JIMÉNEZ-ALEIXANDRE et al., 2000; SIMONNEAUX, 2000; SADLER, 2004b). Ademais, percebemos também uma insuficiência do conhecimento científico para resolver problemas de natureza tão controversa como as questões sociocientíficas (KOLSTØ, 2001; SADLER; ZEIDLER, 2004; HODSON, 2010; CONRADO, 2017), necessitando, como apontado, por exemplo, no trabalho de Carvalho e Leite (2015), que outras posições, principalmente do campo da moral e ética, sejam levadas em consideração e trabalhadas nestes contextos de ensino, pois, como afirmado por Pereira e Trivelato (2009, p.8, grifo nosso), a própria "[...] natureza do problema requer que outras dimensões, que não somente a dimensão científica, sejam necessárias para sua resolução". 
Uma prática didática norteada por QSC também possibilita mais momentos de interação dialógica e desenvolvimento da capacidade argumentativa (trabalhos 03,07,10,18,25,27,29,34), assim como discutido em alguns dos trabalhos. Zeidler et al. (2009) destacam ainda que as QSC podem auxiliar, durante os momentos de discussão em sala de aula, o processo de elaboração de argumentos qualificados em debates, tanto com docentes quanto com discentes. Silva et al. (2011), perceberam, por exemplo, a motivação a participar dos alunos, nas atividades utilizando QSC,

[...] já que estes se sentiram livres para expor suas opiniões de forma espontânea, sem a obrigatoriedade de obtenção de um único posicionamento, numa situação em que o estudante conseguiu estabelecer diálogo com o professor e com seus pares (SILVA et al., 2011, p. 10, grifo nosso).

Não só outros conhecimentos são resgatados, como também as demais dimensões dos conteúdos são mobilizadas (trabalhos 04,12,25,26,27). A partir das QSC, podemos tratar os conteúdos escolares não só numa perspectiva conceitualista, mas que mobilize também as dimensões procedimentais e atitudinais dos mesmos, discutindo, por exemplo, as questões valorativas relacionadas às temáticas controversas tratadas, como abordado em alguns dos trabalhos pesquisados (IDELAND; MALMBERG, 2012; SANTOS; KATO, 2013; CARVALHO; LEITE, 2015; SANTOS et al., 2016). Para Santos et al. (2012, p. 237, grifo nosso), as QSC “além de potencializar o processo de interação em sala de aula, possibilitam o surgimento de situações vivenciais, a discussão de atitudes e valores, e de conceitos de ciência e de tecnologia".

$\mathrm{O}$ combate às visões distorcidas da ciência (trabalhos 12,13,32,34) também é uma das vantagens alcançadas a partir do uso das QSC apontadas em trabalhos do corpus da pesquisa (e. g. ZEIDLER et al., 2009; IDELAND; MALMBERG, 2012; VISSICARO et al., 2016). Jones et al. (2012) afirmam que as QSC, quando trabalhadas em contextos educacionais, permitem que os discentes compreendam melhor pilares que sustentam a prática científica, percebendo de modo mais apropriado os meandros da natureza da Ciência.

\section{Considerações finais}

A partir da análise das propostas de ensino baseado em Questões Sociocientíficas presentes na literatura da educação básica e enquadradas nos critérios da pesquisa, percebemos que se tem, entre uma parcela dos trabalhos, certa concordância acerca da concepção teórica sobre o que são as QSC e suas características principais, bem como há uma homogeneidade nos referenciais adotados nas obras analisadas. Porém, em alguns dos trabalhos, os autores não apresentam explicitamente sua vinculação teórica, ou seja, os referenciais adotados por eles para embasarem suas discussões relativas às QSC. 
Entre as principais dificuldades encontradas durante o uso das QSC estão: a resistência de professores e gestores, devido à demanda exigida a estes e à falta de um currículo orientado para as finalidades de uma educação crítica; a falta de materiais educativos adequados para serem utilizados durante a execução das propostas; a deficiência no processo de formação docente inicial e continuada; e a dificuldade dos próprios discentes ao se depararem com tal estratégia didática. Entretanto, muitas dessas situações de oposição podem estar mais relacionadas a uma resistência geral existente às tendências e propostas inovadoras na educação (que acabam por questionar os modelos vigentes mais tradicionais-tecnicistas) do que particularmente ao uso de QSC.

Apesar destes percalços, o ensino baseado em QSC, segundo a literatura analisada, colabora na construção de uma educação científica de modo contextualizado, traçando as relações entre as esferas CTSA; auxilia a desenvolver a criticidade, visando à formação cidadã para a tomada de decisão e a ação sociopolítica; mobiliza outros conhecimentos e as outras dimensões dos conteúdos envolvidos nas controvérsias discutidas; combate as visões distorcidas da Ciência; e se compromete com um trabalho para a melhoria da capacidade argumentativa e que preze por mais momentos de interação dialógica e participação social. Deste modo, mesmo com as dificuldades apontadas para a adoção do uso de QSC em sala de aula, os trabalhos analisados nos indicam uma série de benefícios que esta ferramenta pode agregar ao Ensino de Ciências.

Contudo, diante dos resultados encontrados nas propostas avaliadas, percebemos que há ainda uma necessidade de (i) abranger um maior número de pesquisas sobre propostas de ensino baseadas em QSC, abarcando, também, a literatura não consultada por esta pesquisa, mas que possui sua relevância dentro do contexto da pesquisa em educação científica (como teses e livros, por exemplo), bem como incluindo outros bancos e bases de dados, uma vez que o presente trabalho avaliou apenas parte das publicações existentes sobre o assunto; e (ii) discutir, planejar, inserir e avaliar ações que visem minimizar as limitações ainda encontradas na implementação de uma didática baseada em QSC, produzindo, por exemplo, materiais educativos apropriados e investindo na inserção das discussões sobre QSC durante a formação tanto inicial quanto continuada dos professores.

\section{Agradecimentos e apoio}

O presente trabalho foi realizado com apoio da Coordenação de Aperfeiçoamento de Pessoal de Nível Superior - Brasil (CAPES) - Código de Financiamento 001. Ao INCTINTREE - CNPQ/CAPES/FAPESB. 


\section{Referências}

AGUIAR, R.C.B.; CABRAL, I.E. A temática saúde nas atas do ENPEC: delineando tendências e apontando demandas de investigação em ciências. In: ENCONTRO NACIONAL DE PESQUISA EM EDUCAÇÃO EM CIÊNCIAS, 6., 2007, Florianópolis. Anais.. Florianópolis, 2007.

ARANHA, M.L.A. Filosofia da educação. 2. ed. São Paulo: Moderna, 1996.

ARENAS, M.L.M.; DÍAZ, M.A.R.; MARTÍNEZ-PÉREZ, L.F. Competencias ambientales em básica primaria a partir del desarrollo de uma unidad didáctica sobre la controversia? vivienda o humedales? Indagatio Didactica, v. 8, n.1, p. 702-720, 2016.

BARBOSA, L.G.D.; LIMA, M.E.C.C.; MACHADO, A.H. Controvérsias sobre o aquecimento global: circulação de vozes e de sentidos produzidos em sala de aula. Revista Ensaio, v. 14, n. 1, p.113-130, 2012.

BARDIN, L. Análise de conteúdo. Lisboa: Edições 70, 2011.

BELL, J. Doing your research Project: a guide for first-time researchers in education, health and social science. 4. ed. England: Open University Press, 2005.

CARVALHO, L.M. de; LEITE, S.Q.M. Educação em Ciências para a vida: construção de documentários baseados em temas sociocientíficos da cidade. In: ENCONTRO NACIONAL DE PESQUISA EM EDUCAÇÃO EM CIÊNCIAS, 10., 2015, Águas de Lindóia. Anais... Águas de Lindóia, 2015.

CERVO, A. L.; BERVIAN, P. A. Metodologia científica. São Paulo: Prentice Hall, 2002.

CONRADO, D.M. Questões Sociocientíficas na Educação CTSA: contribuições de um modelo teórico para o letramento científico crítico. Tese de doutorado em Ensino, Filosofia e História das Ciências - Universidade Federal da Bahia / Universidade Estadual de Feira de Santana, Salvador, 2017.

CONRADO, D.M.; NUNES-NETO, N.F. (Orgs.). Questões Sociocientíficas: fundamentos, propostas de ensino e perspectivas para ações sociopolíticas. Salvador: EDUFBA, 2018a.

CONRADO, D.M.; NUNES-NETO, N.F. Questões sociocientíficas para a aprendizagem de conteúdos conceituais, procedimentais e atitudinais no Ensino de Ciências. In: CONRADO, D.M.; NUNES-NETO, N.F. (Orgs.). Questões Sociocientíficas: fundamentos, propostas de ensino e perspectivas para ações sociopolíticas. Salvador: EDUFBA, 2018b. p. 77-118.

DAL-FARRA, R.A.; NUNES-NETO, N.F. Reflexões sobre Filosofia e História da Biologia e Educação. Acta Scientiae, v. 16, n. 2, p. 370-382, 2014.

DEMO, P. Introdução à metodologia da ciência. 2. ed. São Paulo: Atlas, 1985.

DIONOR, G. A. Propostas de ensino baseado em questões sociocientíficas: uma análise sistemática da literatura acerca do ensino de ciências na educação básica. Dissertação de 
mestrado em Ensino, Filosofia e História das Ciências - Universidade Federal da Bahia/Universidade Estadual de Feira de Santana, Salvador, 2018.

ERIC. Education Resources Information Center. (On-line). 2017. Disponível em: $<$ https://eric.ed.gov/pdf/ERIC_Contributers_Fall2016.pdf>. Acesso em: 7 nov.2017.

FERREIRA, A.C.; QUADROS, A.L.; RODRIGUES, V.A.B. Ensino a partir de temas: é favorecida a apropriação de conceitos científicos? Indagatio Didactica, v. 8, n.1, p.1098$1113,2016$.

FREITAS, R.O.; BRAGA, M. Uma controvérsia sócio-científica em escolas do Rio de Janeiro: relatos de um fracasso. In: SEMINÁRIO ÍBERO-AMERICANO DE CTS, 2., 2010, Brasília. Anais... Brasília, 2010.

GAGLIARDI, R. Los conceptos estructurales en el aprendizaje por investigación. Enseñanza de las Ciencias, v. 4, n. 1, p. 30-35, 1986.

GIL, A.C. Como elaborar projetos de pesquisa. 6. ed. São Paulo: Atlas, 2017.

GIL-PÉREZ, D.; MONTORO, I.F.; ALÍS, J.C.; CACHAPUZ, A.; PRAIA, J. Por uma imagem não deformada do trabalho científico. Ciência \& Educação, v.7, n.2, p.125-153, 2001.

GONÇALVES, R.S.; SILVA, L.F. Abordagem de Temas a Partir do Enfoque CTS na Educação Básica: Caracterização dos Trabalhos Apresentados por Autores Brasileiros, Espanhóis e Portugueses nos Seminários Ibero-americanos CTS. Revista CTS, v.12, n.34, p.223-249, 2017.

HODSON, D. Going beyond STS: towards a curriculum for sociopolitical action. The Science Education Review, v. 3, n. 1, p. 2-7, 2004.

HODSON, D. Science Education as a Call to Action. Canadian Journal of Science, Mathematics and Technology Education, v. 10, n. 3, p. 197-206, 2010.

HODSON, D. Don't Be Nervous, Don’t Be Flustered, Don’t Be Scared. Be Prepared. Canadian Journal of Science, Mathematics and Technology Education, v. 13, n. 4, p. 313 $331,2013$.

HOEG, D.; LEMELIN, N.; BENCZE, J.L. Sociopolitical development of private school children mobilising for disadvantaged others. Cultural Studies of Science Education, v. 10, n. 4, p. 1155-1174, 2015.

IDELAND, M.; MALMBERG, C. Body talk: students' identity construction while discussing a socioscentific issue. Cultury Studies of Science Education, v. 7, p. 279-305, 2012.

JIMÉNEZ-ALEIXANDRE, M.P.; FREDERICO-AGRASO, M. A argumentação sobre questões sociocientíficas: processos de construção e justificação do conhecimento em sala de aula. Educação em Revista, v. 43, p. 13-33, 2006. 
JIMÉNEZ-ALEIXANDRE, M.P.; RODRÍGUEZ A.B, DUSCHL, R.A. "Doing the Lesson" or "Doing Science": Argument in High School Genetics. Science Education, v. 84, p. 757-792, 2000 .

JONES, A.; BUNTTING, C.; HIPKINS, R; MCKIM, A.; CONNER, L.; SAUNDERS, K. Developing Students' Futures Thinking in Science Education. Research in Science Education, v. 42, p. 687-708, 2012.

KAHN, S.; ZEIDLER, D.L. A Case for the Use of Conceptual Analysis in Science Education Research. Journal of Research in Science Teaching, v. 54, n. 4, p. 538-551, 2017.

KOLST $\varnothing$, S.D. Scientific literacy for citizenship: Tools for dealing with the science dimension of controversial socioscientific issues. Science Education, v. 85, n. 3, p. 291-310, 2001.

LECOMPTE, M.; GOETZ, J. Problems of reliability and validity in ethnographic research. Review of Educational Research, v. 52, n. 1, p. 31-60, 1982.

LEVINSON, R. Towards a Theoretical Framework for Teaching Controversial Socioscientific Issues. International Journal of Science Education, v. 28, n.10, p.1201-1224, 2006.

LUCKESI, C. C. Filosofia da Educação. São Paulo: Cortez, 1994.

MARTÍNEZ-PÉREZ, L.F. Questões sociocientíficas na prática docente: ideologia, autonomia e formação de professores. São Paulo: Editora Unesp, 2012.

MARTÍNEZ-PÉREZ, L.F. Cuestiones sociocientíficas em la formación de profesores de ciencias: aportes y desafios. TED: Tecné, Episteme y Didaxis, n. 36, p. 77-94, 2014.

MARTÍNEZ-PÉREZ, L.F.; CARVALHO, W.L.P. Contribuições e dificuldades da abordagem de questões sociocientíficas na prática de professores de ciências. Educação e Pesquisa, v.38, n .03, p. 727-741, 2012.

MARTÍNEZ-PÉREZ, L.F.; CARVALHO, W.L.P.; LOPES, N.C.; CARNIO, M.P.; VARGAS, N.J.B. Abordagem de questões sociocientíficas no Ensino de Ciências: contribuições à pesquisa da área. In: ENCONTRO NACIONAL DE PESQUISA EM EDUCAÇÃO EM CIÊNCIAS, 8., 2011, Campinas. Anais... Campinas, 2011.

MELO, L.M.; PRÍMOLA, N.S.; MACHADO, P.F.L. E-lixo: um tema sociocientífico para aulas de Química com enfoque CTS na educação politécnica. In: ENCONTRO NACIONAL DE PESQUISA EM EDUCAÇÃO EM CIÊNCIAS, 9., 2013, Águas de Lindóia. Anais... Águas de Lindóia, 2013.

MOREIRA, M.C.A.; AMOR, R. Estudo comparativo da sustentabilidade na visão de estudantes em eventos esportivos em Londres e no Rio de Janeiro. In: ENCONTRO NACIONAL DE PESQUISA EM EDUCAÇÃO EM CIÊNCIAS, 10., 2015, Águas de Lindóia. Anais... Águas de Lindóia, 2015. 
MUNDIM, J.V.; SANTOS, W.L.P. Ensino de ciências no ensino fundamental por meio de temas sociocientíficos: análise de uma prática pedagógica com vista à superação do ensino disciplinar. Ciência \& Educação, v. 18, n. 4, p. 787-802, 2012.

NICOLAOU, C.T.; EVAGOROU, M.; LYMBOURIDOU, C. Elementary School Students' Emotions when Exploring an Authentic Socio-Scientific Issue through the Use of Models. Science Education International, v. 26, n. 2, p. 240-259, 2015.

PARASKEVA-HADJICHAMBI, D.; HADJICHAMBIS, A.C.; KORFIATIS, K. How Students' Values are Intertwined with Decisions in a Socio-scientific Issue. International Journal of Environmental \& Science Education, v. 10, n. 3, p. 493-513, 2015.

PEDRETTI, E.; NAZIR, J. Currents in STSE Education: mapping a complex field, 40 years on. Science Education, v. 95, n. 4, 2011.

PEREIRA, R.G.; TRIVELATO, S.L.F. Estudantes do ensino médio utilizam conhecimento científico em seus posicionamentos acerca de questões sócio-científicas? In: ENCONTRO NACIONAL DE PESQUISA EM EDUCAÇÃO EM CIÊNCIAS, 8., 2011, Campinas. Anais... Campinas, 2011.

PEREIRA, R.G.; TRIVELATO, S.L.F. Uma análise sobre as características de argumentos de alunos do Ensino Médio sobre temática sócio-científica. In: ENCONTRO NACIONAL DE PESQUISA EM EDUCAÇÃO EM CIÊNCIAS, 8., 2009, Florianópolis. Anais...

Florianópolis, 2009.

PRAIA, J.; CACHAPUZ, A.; GIL-PÉREZ, D. Problema, teoria e observação em ciência: para uma reorientação epistemológica da Educação em Ciência. Ciência \& Educação, v. 8, n. 1, p. 127- 145, 2002.

RAMÍREZ, N.K.G.; MARTÍNEZ-PÉREZ, L.F. Incidencia del abordaje de una cuestión socio-científica em la alfabetización científica y tecnológica de jóvenes y adultos. Praxis \& Saber, v. 6, n. 11, p. 87-114, 2015.

RAMOS, A.; FARIA, P.M.; FARIA, A. Revisão sistemática da literatura: contributo para a inovação na investigação em Ciências da Educação. Revista Diálogo Educacional, v. 14, n. 41, p. 17-36, 2014.

RATCLIFFE, M.; GRACE, M. Science Education for Citizenship: teaching socio-scientific issues. Philadelphia: Open University Press, 2003.

REIS, P.; GALVÃO, C. Teaching Controversial Socio-Scientific Issues in Biology and Geology Classes: A Case Study. Electronic Journal of Science Education, v. 13, n. 1, p. 1-24, 2009.

SADLER, T.D. Moral and ethical dimensions of socioscientific decision-making as integral components of science literacy. Science Educator, v. 13. p. 39-48, 2004a.

SADLER, T.D. Informal Reasoning Regarding Socioscientific Issues: A Critical Review of Research. Journal of Research in Science Teaching, v. 41, n. 5, p. 513-536, $2004 \mathrm{~b}$. 
SADLER, T.D. Evolutionary theory as a guide to socioscientific decision-making. Journal of Biological Education, v. 39, n. 2, p. 68-72, 2005.

SADLER, T.D.; DONNELLY, L.A. Socioscientific Argumentation: The effects of content knowledge and morality. International Journal of Science Education, v. 28, n. 12, p. $1463-$ 1488, 2006.

SADLER, T.D.; ZEIDLER, D.L. The morality of socioscientific issues: Construal and resolution of genetic engineering dilemmas. Science Education, v. 88, n. 1, p. 4-27, 2004.

SANTOS, J.C.; CONRADO, D.M.; NUNES-NETO, N.F. Questões sociocientíficas no ensino fundamental de ciências: uma experiência com poluição de águas. Indagatio Didactica, v. 8, n. 1, p. 1051-1067, 2016.

SANTOS, C.G.M.M.; KATO, D.S. Limites e possibilidades do uso de situações problemas como recurso pedagógico: os temas controversos sócio científicos e as relações CTSA como perspectivas para o Ensino de Ciências. In: ENCONTRO NACIONAL DE PESQUISA EM EDUCAÇÃO EM CIÊNCIAS, 9., 2013, Águas de Lindóia. Anais... Águas de Lindóia, 2013.

SANTOS, M.S.; AMARAL, C.L.C.; MACIEL, M.D. Tema sociocientífico "cachaça" em aulas práticas de química na educação profissional: uma abordagem CTS. Revista Ensaio, v. 14, n. 1, p. 227-239, 2012.

SANTOS, P.G.F.; LOPES, N.C., CARNIO, M.P.; CARVALHO, L.M.O.; CARVALHO, W.L.P. A abordagem de Questões Sociocientíficas no ensino de Ciências: uma compreensão das sequências didáticas propostas por pesquisas na área. In: ENCONTRO NACIONAL DE PESQUISA EM EDUCAÇÃO EM CIÊNCIAS, 8., 2011, Campinas. Anais... Campinas, 2011.

SCHIMIDT, D.T.; SUTIL, N. O jogo digital Minecraft como um espaço de discussão, reflexão e ação a partir dos pressupostos da educação CTSA. Indagatio Didactica, v. 8, n. 1, p. 1863-1880, 2016.

SCIELO. Scientific Eletronic Library Online. (On-line). 2017. Disponível em: $<$ http://www.scielo.org/php/index.php?lang=pt>. Acesso em: 07 nov.2017.

SCOPUS. (On-line). 2017. Disponível em:

$<$ https://www.elsevier.com/solutions/scopus/content>. Acesso em 07 nov.2017.

SILVA, F. L.; PESSANHA, P. R.; BOUHID, R. Abordagem do tema controverso Radioatividade/Energia Nuclear em sala de aula no Ensino Médio - Um Estudo de Caso. In: ENCONTRO NACIONAL DE PESQUISA EM EDUCAÇÃO EM CIÊNCIAS, 8., 2011, Campinas. Anais... Campinas, 2011.

SILVA, K.M.A. Questões sociocientíficas e o pensamento complexo: tecituras para o Ensino de Ciências. Tese de Doutorado em Educação - Universidade de Brasília, Brasília, 2016.

SIMONNEAUX, L. Cómo favorecer la argumentación sobre las biotecnologías entre el alumnado. Alambique - Didatica de las Ciencias Experimentales, n. 25, p. 27-44, 2000. 
SIMONS, G.F.; FENNIG, C.D. (Eds.). Ethnologue: Languages of the World. 20. ed. Texas: SIL International. Disponível em: <http://www.ethnologue.com>. Acesso em: 16 nov. 2017.

SOLBES, J. Contribuición de las cuestiones sociocientíficas al desarrollo del pensamiento crítico (I): introducción. Revista Eureka sobre Enseñanza y Divulgación de las Ciencias, v. 10, n. 1, p.1-10, 2013.

SOUSA, P.S.; GEHLEN, S.T. Questões Sociocientíficas no Ensino de Ciências: algumas características das pesquisas brasileiras. Ensaio Pesquisa em Educação em Ciências, v. 19, p. 1-22, maio. 2017.

VENTURI, T.; MOHR, A. Análise da Educação em Saúde em publicações da área da Educação em Ciências. In: ENCONTRO NACIONAL DE PESQUISA EM EDUCAÇÃO EM CIÊNCIAS, 8., 2011, Campinas. Anais... Campinas, 2011.

VISSICARO, S.P.; FIGUEIRÔA, S.F.M.; ARAÚJO, M.S. Questões sociocientíficas nos anos iniciais do Ensino Fundamental: o tema água em evidência. Indagatio Didactica, v. 8, n. 1, p. 1596-1609, 2016.

WU, Y.T.; TSAI, C.C. The Effects of Different On-line Searching Activities on High School Students' Cognitive Structures and Informal Reasoning Regarding a Socio-scientific Issue. Research in Science Education, v. 41, n. 5, p. 771-785, 2011.

ZEIDLER, D.L.; SADLER, T.D.; SIMMONS, M. L.; HOWES, E.V. Beyond STS: a research-based framework for socioscientific issues education. Science Education, v. 89, p. 357-377, 2005.

ZEIDLER, D.L.; SADLER, T.D.; APPLEBAUM, S.; CALLAHAN, B.E. Advancing Reflective Judgment through Socioscientific Issues. Journal of Research in Science Teaching, v. 46, n. 1, p. 74-101, 2009.

ZEIDLER, D.L.; NICHOLS, B.H. Socioscientific Issues: theory and practice. Journal of Elementary Science Education, v. 21, n. 2, p. 49-58, 2009.

\section{SOBRE OS AUTORES}

GRÉGORY ALVES DIONOR. Licenciado em Ciências Biológicas (UNEB/DEDC-X). Especialista em Docência no Ensino Superior (UniBF). Mestre em Ensino, Filosofia e História das Ciências, pelo Programa de Pós-Graduação em Ensino, Filosofia e História das Ciências (UFBA/UEFS), no qual também está cursando seu doutorado. Atualmente é Professor Substituto do curso de Licenciatura em Ciências Biológicas da Universidade do Estado da Bahia - Campus X/DEDC. É coordenador voluntário da Residência Pedagógica e do PIBID, ambos vinculados ao curso no qual leciona. Está vinculado ao Laboratório de Ensino, Filosofia e História da Biologia - LEFHBio (IBio-UFBA). Desenvolve pesquisas acerca de Ensino de Ciências e Biologia, Questões Sociocientíficas, Educação CTSA e Formação de Professores.

DÁlia MEliSSA CONRADO. Bióloga, Doutora em Ensino, Filosofia e História das Ciências (2017, PPGEFHC - UFBA/UEFS-BA). Mestre e Doutora em Ecologia (2013, 
PPGECOBIO - UFBA-BA). Bacharel em Ciências Biológicas (2002, UEM-PR). Licenciada em Biologia (2015, FACIBA-BA). Pesquisadora do Laboratório de Ensino, Filosofia e História da Biologia (LEFHBIO-BA) e do Instituto Nacional de Ciência e Tecnologia em Estudos Interdisciplinares e Transdisciplinares em Ecologia e Evolução (INCT-INTREE), sediado na UFBA. Tem experiência nas áreas de Educação Científica (Educação CiênciaTecnologia-Sociedade-Ambiente e Questões Sociocientíficas), Educação em Saúde, Ética Ambiental e Fisiologia Humana. Foi pesquisadora visitante e fez estágio de pós-doutoramento (2015) no IAS-Research Group, Centre for Life, Mind and Society, da Universidad del País Vasco, San Sebastián, Espanha. Atualmente, é Professora Visitante da Faculdade de Educação, da Universidade Federal da Grande Dourados, MS

LIZIANE MARTINS. Liziane Martins possui graduação em Licenciatura em Ciências Biológicas pelo Centro Universitário Jorge Amado (UNIJORGE, 2006), especializações em Citogenética Humana pela Universidade Católica do Salvador (UCSAL, 2008) e Formação Docente Ensino Superior: abordagens pedagógicas contemporâneas (UNIJORGE, 2011), mestrado (UFBA/UEFS, 2010) e doutorado em Ensino, Filosofia e História das Ciências, pela Universidade Federal da Bahia/Universidade Estadual de Feira de Santana (UFBA/UEFS, 2016). Atualmente é pesquisadora e professora da Universidade do Estado da Bahia (UNEB) e da Universidade Federal do Sul da Bahia (UFSB). Realiza pesquisas nas áreas de Formação de Professores, Biologia Teórica, com ênfase em Ensino, Filosofia e História da Biologia, e Educação em Saúde, atuando principalmente nos seguintes temas: interface saúde-educação, literacia em saúde, análise de conteúdo de Livro Didático de Biologia, Questões Sociocientíficas para o Ensino de Ciências/Biologia e mobilização de dimensões conceituais, procedimentais e atitudinais em intervenções pedagógicas.

NEI DE FREITAS NUNES NETO. Nei de Freitas Nunes-Neto é Professor Adjunto da Faculdade de Ciências Biológicas e Ambientais, da Universidade Federal da Grande Dourados, desde janeiro/2018. Coordena o Grupo Colaborativo de Pesquisa e Prática em Educação e Filosofia, da FCBA/UFGD. De 2010 a 2017, foi professor do Instituto de Biologia, da Universidade Federal da Bahia (UFBA). É professor colaborador do Programa de Pós-Graduação em Ensino, Filosofia e História das Ciências (UFBA/UEFS). É um dos coordenadores de projetos do Instituto Nacional de Ciência e Tecnologia em Estudos Interdisciplinares e Transdisciplinares em Ecologia e Evolução (INCT IN-TREE), que reúne cerca de 300 pesquisadores de várias instituições brasileiras e estrangeiras. No IN-TREE coordena projetos ligados a educação, epistemologia e ética. Em 2015, foi pesquisador visitante no Centro para Vida, Mente e Sociedade, do Departamento de Lógica e Filosofia da Ciência, da Universidade do País Basco. Obteve doutorado em Ecologia (UFBA, 2013), mestrado em Ensino, Filosofia e História das ciências (UFBA/UEFS, 2008), e bacharelado em Ciências Biológicas (UFBA, 2006). Ministra palestras e participa de mesas-redondas em eventos no Brasil e no exterior, sobretudo nas áreas de educação e filosofia. Realiza atividades de ensino, pesquisa e extensão em Educação em Ciências e Filosofia da Biologia.

Recebido: 01 de fevereiro de 2019.

Revisado: 04 de agosto de 2019.

Aceito: 20 de setembro de 2019. 